\title{
Implementing sustainable forests: A Canadian commitment
}

\author{
by Paul Griss
}

Sustainable Forests: A Canadian Commitment promises some fundamental changes in the approach to forest management in Canada. Achieving these objectives will require political will and creative and innovative approaches to securing the necessary human and financial resources. In particular, increased attention is required to non-timber values, changing roles and responsibilities, public participation, research, and reporting, if the strategy is to be implemented successfully. Governments must demonstrate leadership in these areas, but are impeded by structural, political, and financial constraints.

Over the past five years, a variety of national, provincial and sectoral initiatives have reached common conclusions with respect to the range of values of Canada's forests and the need to sustain them. There is also an emerging consensus that forests should be viewed as ecosystems and that human activity in the forests should be managed within that context. The speed at which these ideas have gained acceptance is remarkable.

This has resulted in an escalation of expectations in terms of what the public demands both from our forests and from forest managers. It is clear that a wide range of conservation, environmental, aboriginal, labour, community, and other groups want to have a greater role in forest management and that they will expect to see real changes. Forest management decision-making will need to be reshaped as a result of newly accepted concerns, and the roles and responsibilities of all stakeholders must adapt to new realities.

Virtually all stakeholders are now at least in general agreement on the principles that define sustainable forests. The challenge is to translate those principles into action. As the owners of much of Canada's forested landbase, governments must demonstrate leadership in this process. Indeed, with the publication of Sustainable Forests: A Canadian Commitment, Canada's national forest strategy, the Canadian Council of Forest Ministers explicitly undertook this responsibility.

To date, this commitment has been met with enthusiasm and goodwill. However, the really tough decisions have yet to be made and a number of impediments to progress, many unforeseen, will need to be overcome to satisfy the raised expectations that have been created. Achieving the goals of the national forest strategy will require substantial political will and innovative approaches to the planning and funding of forest management.

Paul Griss is a former executive director of the Canadian Nature Federation, and was a member of the steering committee established by the CCFM to co-ordinate the national forest strategy and the National Forest Congress. He is presently an independent consultant.
La Durabilité des forêts: un engagement canadien laisse entrevoir certains changements fondamentaux au niveau de l'approche utilisée en aménagement forestier au Canada. L'atteinte de ces objectifs nécessitera une volonté politique ainsi que des approches créatives et innovatrices afin d'obtenir les ressources humaines et financières nécessaires. Plus particulièrement, une plus grande attention doit être apportée aux valeurs non-ligneuses, à la modification des rôles et des responsabilités, à la participation du public, à la recherche et à la diffusion, pour que la stratégie puisse être implantée avec succès. Les gouvernements doivent faire preuve de leadership dans ces domaines, mais en sont empêchés par des contraintes structurelles, politiques et financières.

\section{Putting the Strategy Into Action}

It has now been 18 months since the release of Sustainable Forests: A Canadian Commitment. Like all documents of its kind, the strategy is of necessity general in nature. The commitment, though, is to do more of everything, and to do it better than has been done in the past. Despite all of the goodwill that surrounds the national forest strategy, a tremendous amount of work remains to be done to determine how, or even if, this objective can be reached.

Initially, governments undertook to develop action plans for the implementation of Sustainable Forests: A Canadian Commitment within their jurisdictions. This has imposed a considerable time lag between the adoption of the strategy and the identification of the concrete actions that will interpret its commitments. Hence, it will be difficult to credit the strategy with visible progress "on-the-ground" for some time. In the near term, governments will be able to do little more than identify how their existing programs or activities qualify as initiatives of the strategy in their progress reports. These are important, but it will be some time before the fundamental changes implicit in the strategy receive attention.

In the absence of measurable short term progress, two problems can be expected. The first is frustration, particularly on the part of those whose expectations have been raised. This could threaten the new partnerships and constructive interaction that have been emerging among all forest stakeholders over the past few years.

More importantly, the timespan between commitment and implementation is going to make it extremely difficult to sustain the momentum that has been built during the process that led to the strategy. New governments will take power, new bureaucrats and corporate executives will be on the scene, governance of NGOs will change, and the social and economic context will evolve. These transitions could lessen the sense of ownership of the strategy and make it more difficult to secure the political will and the resources necessary to fulfil its commitments. Even in the short time since the strategy was adopted, there have been some significant changes that are no doubt going to seriously impede progress.

Global economic conditions have imposed restraints upon Canada's forest sector. The red ink has continued to flow 
at forest companies, reducing their willingness to consider any activities that might add to their costs, whatever the long term benefits. Resource management agencies have been in turmoil in much of the country as a result of mergers, reorganizations and budget cutbacks, resulting in the loss of senior staff and the curtailing of programs. Forestry Canada, which played a lead role in developing the national forest strategy, has been particularly hard hit, losing the Forest Resource Development Agreements and being downgraded and merged with Energy, Mines and Resources Canada. Governments have changed in some jurisdictions and a number of ministers who signed the Canada Forest Accord have lost their appointments.

These factors can only compromise Canada's ability to deliver on its national and international commitments to sustainable forests. Sustainable Forests: A Canadian Commitment calls for more of everything; but all stakeholders in forest management are having to make do with less.

\section{The Need for Leadership}

The pressure on Canada's forests and forest users is increasing. The "big picture" has changed very little since the national forest strategy was released. While a few new and innovative approaches to forest management, such as model forests and community forestry, are being tested across the country, they are largely in an experimental phase. Conflict is still the order of the day in the public perception of forest management. The confrontation at Clayoquot Sound defines forest management in Canada for much of the world and, by extension, the customers for Canada's forest products.

In response to concerns about forest management worldwide, a variety of initiatives related to sustainable forests are in development. These range from efforts to formulate a Global Forests Convention, discussed at the United Nations Conference on Environment and Development, to independent processes, such as the work of the Forest Stewardship Council. The latter is one of many trade-related exercises designed to develop eco-labelling programs to assure consumers that forest products are produced in a sustainable fashion.

Despite all of the broad policy statements and commitments from governments and industry, though, there is not yet a consensus on what sustainable forests mean in practice. Consequently, the term sustainability is thrown around loosely by all participants in forest management debates. The Government of British Columbia and MacMillan Bloedel are even engaged in a legal battle over different interpretations of sustainability - as if a court is in a position to make such a determination. In the absence of clear policy direction, all actions can be questioned as to their sustainability with equal veracity!

On the world forestry stage, Canada has been equal parts hero and villain. We have been a leader in pursuing the concept of a Global Forests Convention, in developing criteria and indicators for sustainable forests, and in involving NGOs in policy processes. On the other hand, forest management in Canada is being portrayed in a negative light by some international NGOs, and Canada is one of the prime targets for eco-labelling of forest products as a result. All of the policy statements and public relations campaigns will not make any difference to Canada's image - it is what we do that counts.
In order for Canada to position itself to meet these challenges, leadership is required across the broad spectrum of forest management. That leadership must come from the owners of the forests - primarily the provincial governments.

\section{Major Challenges in Sustainable Forestry}

"In the end, management for sustainability will be designed with the combined goals for all uses in clear view from the outset, and not as a sequence of constraints to whatever value comes first. It is not possible to manage a dynamic system towards a multi-factor goal solely by constraint of one factor... The best that can be said for non-timber values at present is that they enter the management design process late, and as constraints, never as part of the objective."

\section{From the report of the Forest Sectoral Committee of} the New Brunswick Round Table on Environment and Economy Task Force on Sustainable Development (1990).

Until recently, forest management in Canada has meant timber management, with other values largely dealt with as constraints, whether this be "withdrawals" of land for parks, or the modification of forestry operations to retain or provide habitat for selected species. Most of the other forest values now acknowledged have previously been given only token, if any, attention.

The new language being used to discuss sustainable forestry turns our present system on its head. Tinkering with a system oriented to timber management will provide some gains, but will never enable us to achieve the overall objective, which is to place the well-being of the forest ahead of its component parts and all its potential uses. If we are going to succeed, we are going to have to make some tough decisions in the following areas.

\section{(a) Respecting all Forest Values}

The clear message arising from documents like Sustainable Forests: A Canadian Commitment is that timber production is only one of many goals for Canada's forests, and it is not always the pre-eminent goal. Implementing commitments to improved forest management, and integrating all values into decision-making, requires a fundamental shift in the approach to forest management across Canada. To be sustainable, we must define timber management within the context of forests, instead of forest management in the context of timber. Changing the status quo in this area is perhaps the biggest challenge in forest management today.

The single major obstacle to the achievement of this objective is the narrow operational focus of all natural resources agencies across Canada. Although the mandates of most of these agencies indicate that they should be in a strong position to bring a range of perspectives to bear on issues, they are heavily oriented toward exploitation. Even with recent attention to non-game and endangered species, for example, wildlife management in Canada is still largely equated with game and furbearer management. Fisheries departments concentrate on the needs of anglers and commercial fishers. Parks departments are much more oriented toward recreation and visitor services than they are to resource conservation. Forest services deal primarily with timber management. The needs of most forest species are addressed by default, or fall between the cracks. 
This narrow approach has arisen because these agencies evolved to allocate resources and control human activities. Addressing issues beyond the scope of the legislation and policies which drive their programs is extremely difficult, particularly in times of fiscal restraint. In fact, despite years of integrated resource management most of these agencies are still unable to fully integrate their present responsibilities, let alone incorporate a wider range of values.

Across the country, all jurisdictions are attempting to identify objectives for biodiversity, old-growth, wildlife, protected areas, recreation, aesthetics, and a variety of other values. However, each of these objectives can be measured in different ways and comparisons between methods of measurement may not be possible. Worse, objectives may be contradictory leading to difficulties in integration. A more holistic view is required which establishes objectives for the forest, from which all other values will flow. At present this is not structurally possible.

No forest management or natural resources agency in Canada has the human or financial resources to enable the requisite broadening of its operational focus. Many have restructured or reorganized, for a variety of reasons, but as in the former Soviet Union the philosophy has changed but most of the same apparatchiks are in charge. Forest companies are caught in the same trap. Few employ even a biologist, let alone people who are expert in the other values of forests. New objectives require new skills, and new priorities require commensurate funding.

Consequently, natural resources agencies and forest companies can do little more than to try to address the changing approach to forest management with minimal disruption to the status quo. The predominant thinking remains geared towards incorporating non-timber values into a system oriented heavily toward timber management. A first step in the movement towards sustainable forests is for all government agencies to examine their mandates, policies and legislation to ensure that they are not working to the detriment of new objectives. In the short term, agencies unable to acquire the necessary expertise or to enhance or reallocate funding will have to establish partnerships with those agencies, both governmental and nongovernmental, that can contribute to this broader vision.

\section{(b) Changing Roles and Responsibilities}

The values of forests, and the responsibilities for safeguarding them, are held by a wide variety of government and non-government agencies. One single agency can not hope to address all of the issues occurring on the forest landbase. Therefore, managing on an ecosystem or sustainable development basis requires more than simply reorganizing existing natural resources agencies along ecosystem lines. That is important but by itself will not address the issues. Interagency co-operation needs to be fostered, and indeed imposed where necessary, to ensure that all programs and activities are complementing each other.

More importantly, as more and more players become involved in forest management decision making, governments are going to have to decentralize authority in order to develop the flexibility that is necessary to take full advantage of partnership opportunities. For government agencies with "command and control" responsibilities, this will no doubt be difficult, and few can be expected to have the necessary skills to undertake this very different role successfully. However, the actions necessary to ensure sustainable forests will vary from region to region, and no single approach can be applicable everywhere. It is far better to have general objectives for the jurisdiction, and promote flexibility in the achievement of those objectives on a regional basis.

The relationships with major users of the forest must also evolve. Forest companies, for example, are now expected to accept responsibility for conserving a wider range of values in their operations. It is not clear whether governments are prepared to provide the necessary financial incentives to encourage them to do so, nor whether the public will support the transfer of responsibility for many of these values from the government to private corporations. The necessary changes to the relationship between industry and government could be the most controversial outcome of the national forest strategy.

\section{(c) Involving the Public in Forest Management}

The partnerships established during the development of Sustainable Forests: A Canadian Commitment need to be reflected in forest management on a provincial and also a regional basis. In fact, there is no reason why every forest management area should not have an advisory body, comprised of individuals and organizations who embody the many values held for the forests of the region. Such bodies could assist in co-ordinating the development of ongoing constructive partnerships in forest management and in averting forest management conflicts. This is the concept behind "round tables" and a variety of other multistakeholder fora.

The Ontario Forest Industries Association, in its code of forest management practice, has recognized that public input and other values must be incorporated early into the planning process. Processes such as British Columbia's Commission on Resources and the Environment are also exploring new ways of bringing traditional adversaries to the table. The Model Forests program, established by Forestry Canada, is experimenting with new ways of doing business in the forest through partnerships in forest management.

These types of public involvement processes are largely experimental. Partnerships are difficult to establish and confict still exists, but if properly handled conflict can be minimized and not allowed to impede progress in other areas. At this stage, potential partnerships need to be explored creatively and carefully, and fostered through their early stages of operation. Not all are going to work, or to find the results of their work unchallenged, as is being demonstrated in Clayoquot Sound.

Involving the public in forest management is a complex issue that requires different solutions for different problems. For example, single issue or site specific groups will be able to play only a limited role in addressing broader forest management policy questions. One of two things happens - either undue attention is provided to the issue of concern to the group, frustrating other participants, or the converse is true. On the other hand, as one moves into the development of site-specific or issue-specific plans, familiarity with the region or the technical aspects of the issue commands greater weight. These latter issues are too complex to be decided either in the courts or by referenda. 
Much of the conflict surrounding forest management is structural and is related to the decision-making process. Involving the public and incorporating other values late in the decision making process only allows for mitigation, and mitigation is not sustainable development. Early, constructive and ongoing attention to public concerns will help to avoid problems and ensure commitment from all partners. The only way to effectively counteract misinformation and prevent conflict and confrontation is to open the doors.

\section{(d) A Credible and Practical Information Base}

Even if all values are respected and the public is involved, how do we measure progress? Virtually all statements about sustainable forests are prefaced by a discussion of what we don't know. It is illustrative of the level of debate, though, that all stakeholders view their own "facts" to be unassailable! Increased research and better information are demanded by all stakeholders, but if we don't know what we want, how are we going to get there? And how will we know where we are going if we are not prepared to acquire and cultivate the talent, and invest the time and energy into research that will give us the answers.

The changing perception of forests has changed the clientele for forestry research. The emphasis must be broadened to address all forest values and not just industrial interests. Research programs oriented to understanding our natural environment, and forest ecosystems in particular, will have to be enhanced substantially. Research needs to be expanded to new areas of study, including the quantification of nontimber values and the incorporation of traditional knowledge into planning.

Research, though, tends to be one of the first areas cut in times of fiscal restraint. Increased emphasis is given to the practical application of research findings, particularly if a "client" other than government is contributing to the costs. Research is a long term commitment. We can not keep qualifying our statements on forests with disclaimers about our lack of knowledge and still retain credibility for our present actions unless we are demonstrating a strong commitment to finding the information we need.

\section{(e) Reporting our Progress}

Even if we do have current and accurate information, who is going to believe us when we report on progress? All users of the forest have responsibility for its health, and therefore a vested interest in reporting success or failure in forest management depending on their perspective. This affects the credibility of all stakeholders, including those who are critical of forest management.

Only independent assessments can bridge the credibility gap. Developing the methodology and expertise to apply independent audits of forest management is a daunting task given today's state of knowledge. Nevertheless, we don't have to wait for perfect knowledge before proceeding - we can audit what we are doing now. Ernst \& Young, for example, is developing a methodology for conducting a forest management audit as a partner in the Lake Abitibi Model Forest.

At the very least, an independent assessment of the state of affairs in an area under forest management will be a great equalizer in the forest management debate. All sides are guilty at present of spouting undocumented facts, making unfounded assumptions or even allegations, and in general presenting any information in such a way as to provide the most favourable slant on their self-interest, whatever its validity.

An independent appraisal would keep all parties honest. It would test the assumptions and claims made by all stakeholders, and identify gaps in the information base. It will be interesting to see which companies or government agencies have sufficient courage for their convictions to contribute to the development of forest management audits by submitting themselves to such a test.

\section{Conclusion}

The adoption of Sustainable Forests: A Canadian Commitment, and related policy initiatives, holds great promise for improvements in forest management in Canada. The implementation of these commitments is compromised by a number of obstacles, principally the operational focus and constraints of government agencies responsible for resource management. Overcoming these obstacles will be a tremendous management challenge, but the cost of failure will be substantial.

If governments can make a concerted effort to confront the challenges imposed by their commitments to sustainable forests, a creative and dynamic approach to forest management will emerge. The emphasis will be on maintaining a healthy forest environment and sustaining the full range of values of the forest. This will include a strong and diverse forest economy and will be attained through a multitude of successful partnerships. Governments will be one of those partners, providing clear policy direction, implemented through a flexible management style that responds to regional needs and concerns. The information base on Canada's forests and their values will be enhanced considerably, and the results of forest management will be reported in a credible and impartial manner.

Implementing Sustainable Forests: A Canadian Commitment is Canada's best hope for ensuring a sustainable future for its forests. Governments stimulated the partnerships that led to the development of this strategy, and they should ensure that they are not the ones standing in the way of its success. 